\title{
DETECTING DIFFERENTIAL ITEM FUNCTIONING IN 2019 BECE BASIC SCIENCE MULTIPLE CHOICE ITEMS ADMINISTERED IN SCHOOLS IN RIVERS STATE, NIGERIA
}

\author{
Dr. Wokoma T. Abbott. \\ Government Technical College, Port Harcourt, Rivers State, Nigeria
}

Article DOI: https://doi.org/10.36713/epra7431

DOI No: 10.36713/epra7431

\begin{abstract}
The study investigated items of 2019 basic science multiple choice, basic education certificate examination (BECE), conducted by the Rivers state ministry of education for junior secondary school three certification. The study attempted to detect differential item functioning of the administered items on urban and rural JSS3 students in Rivers State. A sample size of 240 students drawn from the entire JSS3 population in the state using multistage random sampling technique were used for the study; 120 from urban and 120 from rural schools. Comparative research design was adopted as the framework in this study. The 60 multiple choice 2019 basic science BECE items were used as instrument for data collection which were administered to the students. Items were dichotomously scored. $R$ software was used for item analysis to determine difficulty and discrimination parameters in Two Parameter Logistic Model (2PLM) of Item Response Theory (IRT). $R$ was also adopted to detect deferentially functioning items using Mantel-Haenszel DIF detection method. The study compared results between urban and rural students item characteristic curves, parameters, chi-square statistics, and p-values. It was discovered that urban students found more of the 2019 basic science BECE items easier than their counterparts in the rural areas. The study also revealed that some items deferentially functioned between the two groups when used to assess them. Based on the findings, it was recommended that basic science items for such assessment should be thoroughly checked for DIF, and if found, eliminated or edited before use. Both urban and rural students should be placed on the same condition of learning.
\end{abstract}

KEYWORDS: Item Response Theory, Differential Item Functioning

\section{INTRODUCTION}

Students in junior secondary schools are given certification examination at the end of their three years academic programme. This examination, known as Basic Education Certificate Examination (BECE) or Junior School Certificate Examination (JSCE), is conducted by the Rivers State Ministry of Education for all junior secondary school three (JSS3) students in public and private schools in Rivers state. This examination is in accordance with the 6-3-3-4 education policy in Nigeria.

The Rivers State Ministry of Education (MOE) assess students on the basic education subjects and certify them to proceed to the next level (Senior Secondary School). The certification is based on the number of credit passes obtained. Students are expected to pass six subjects including English language, mathematics, basic science, business studies, etc. This criterion is set as the standard to evaluate all students from the different regions (rural, semi-urban and urban), socioeconomic disposition of parents/guardians, teaching strength and aids available in schools. The BECE being conducted on only the cognitive domain also calls for concern.

The BECE is a high stake and a large scale test. The items used in all the subjects should have stable psychometric dimensions. Items parameters such as difficulty discrimination and guessing indices should remain constant during assessment of both rural, semi-rural and urban subgroups of students. Change in these items characteristics during assessment is referred to as differential item functioning (DIF). This change negate the invariance assumption of item response theory (IRT), which states that item parameter indices should remain the same for subgroups of the same population during assessment (Goldstain, 1983; Wollack, Sung \& Kang; 2006; Li, 2008). 
DIF (uniform and non-uniform) and item parameter drift (IPD) are almost similar concepts. Both are violations of the item parameter invariance assumption of IRT. DIF explains change in item characteristics when samples of the same population are measured repeatedly with the same instrument (Pine, 1977; Goldstein, 1983; Bock, Muraki \& Pfeiffenberger, 1988; Holland \& Wainer, 1993; Wollack, Sung \& Kang; 2006). IPD explains the change in item parameter indices at different times or occasions of testing individuals of the same ability on a task. This difference can lead to lowering of reliability and validity of tests, as well as biases in person and parameter estimation (Babcock \& Albano, 2011; Bulut, Stanke, Rodriguez, Palma Vue, \& Cabrera, 2013).

All students progressing from JSS1 through JSS3 are bound to pass through differing emotional, physical and socioeconomic experiences in and outside the classrooms, which in turn may modify their character. Strength and styles of instruction adopted for teaching and learning in the different school settings, the types and number of teaching aids available in the various schools, and the level of supervision of learning activities are not the same in the schools across the state. These may lead to different experiences in students of the same level.

The plethora of differences in the learners, learning methods, environmental and social dispositions were the factors that aroused the researcher's interest. This study empirically investigated the number of items present in 2019 basic science objective items that exhibited difference in difficulty and discrimination parameters.

In the course of this study, the researcher intended to ascertain the presence of DIF items in the 2019 basic science BECE conducted by ministry of education in Rivers State. The following research questions and hypothesis were formed to guide this study.

\section{RESEARCH QUESTIONS.}

1. To what extent do items of 2019 basic science BECE differ in difficulty indices during testing between rural and urban JSS3 students in Rivers State?

2. To what extent do items of 2019 basic science BECE differ in discrimination indices during testing between rural and urban JSS3 students in Rivers State?

3. How many items of 2019 basic science BECE are DIF items?

\section{HYPOTHESIS.}

1. There are no DIF items of 2019 basic science BECE.

\section{METHODOLOGY}

Sample: All the JSS3 students in both private and public schools formed the population of this study. A total of 12 schools were randomly selected for the study using stratified random sampling; six from urban and six from rural. A total of 20 students were also randomly selected from each of the 12 schools. So, the total number of the students used for this study was 240; 120 from rural schools and 120 from urban schools.

\section{Instrument for Data Collection}

The 2019 Rivers State MOE BECE Basic Science objective (section A) items were used for the study. This had 60 multiple choice items. These items were administered to JSS3 students in a normal classroom examination setting in their schools. Items were dichotomously scored ( 1 for correct and 0 for incorrect) thereafter.

\section{Analysis}

After items were dichotomously scored, $\mathrm{R}$ software was used to determine difficulty (b) and discrimination (a) parameters. Two-parameter logistic model (2PLM) of IRT was adopted in the analysis and the associated packages were used in the item parameter analysis. This was because the packages provided a framework for IRT analyses for dichotomous data under a marginal Maximum Likelihood approach (Rizopoulos, 2006).

Difficulty and discrimination parameter analyses were carried out using on the dichotomously scored items using ltm package. Other $\mathrm{R}$ packages were also used to detect DIF in the items. Some methods of DIF detection are Transformed Item Difficulty (TID), Mantel-Haenzel, Standardization, Logistic regression, Breslow-ay, Lord Chi-square test and Raju's area methods. The item characteristic curve showed the plots of all the 60 items. 


\section{RESULTS}

$\boldsymbol{b}$ is Difficulty parameter, $\boldsymbol{a}$ is Discrimination parameter.

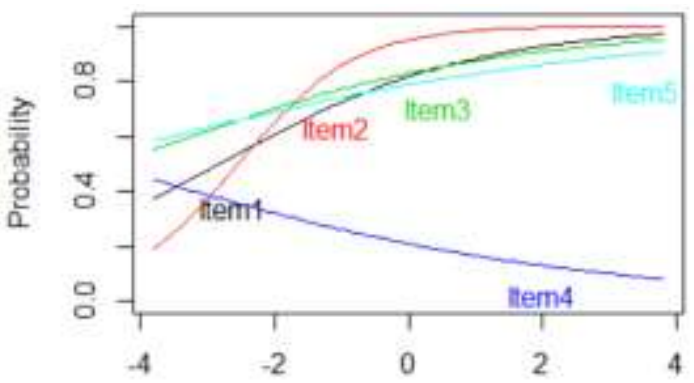

Fig. 1

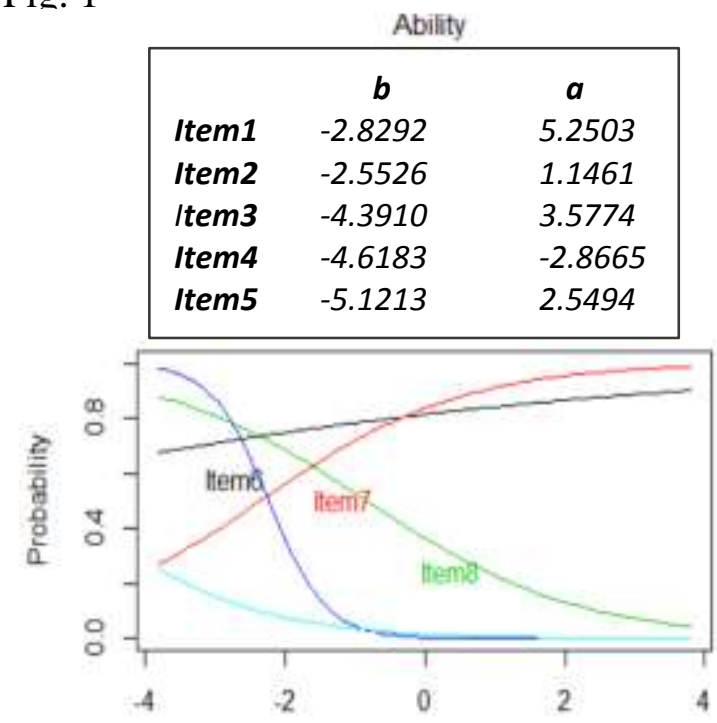

Fig. 3

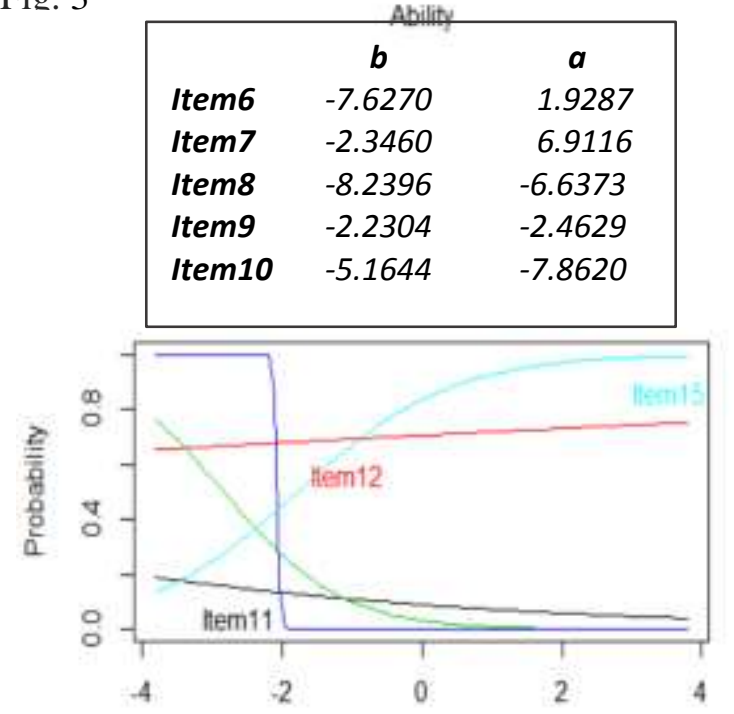

Fig. 5

Ability

\begin{tabular}{|ccc|}
\hline & \multicolumn{1}{c}{$\boldsymbol{b}$} & \multicolumn{1}{c|}{$\boldsymbol{a}$} \\
Item11 & -1.0325 & -2.2339 \\
Item12 & -1.3999 & 6.2154 \\
Item13 & -2.8330 & -1.1906 \\
Item14 & -2.0715 & -4.5074 \\
Item15 & -1.7689 & 9.0927 \\
\hline
\end{tabular}

(C) 2021 EPRA IJMR | www.eprajournals.com |

Fig. 2

Fig. 4

Fig. 6
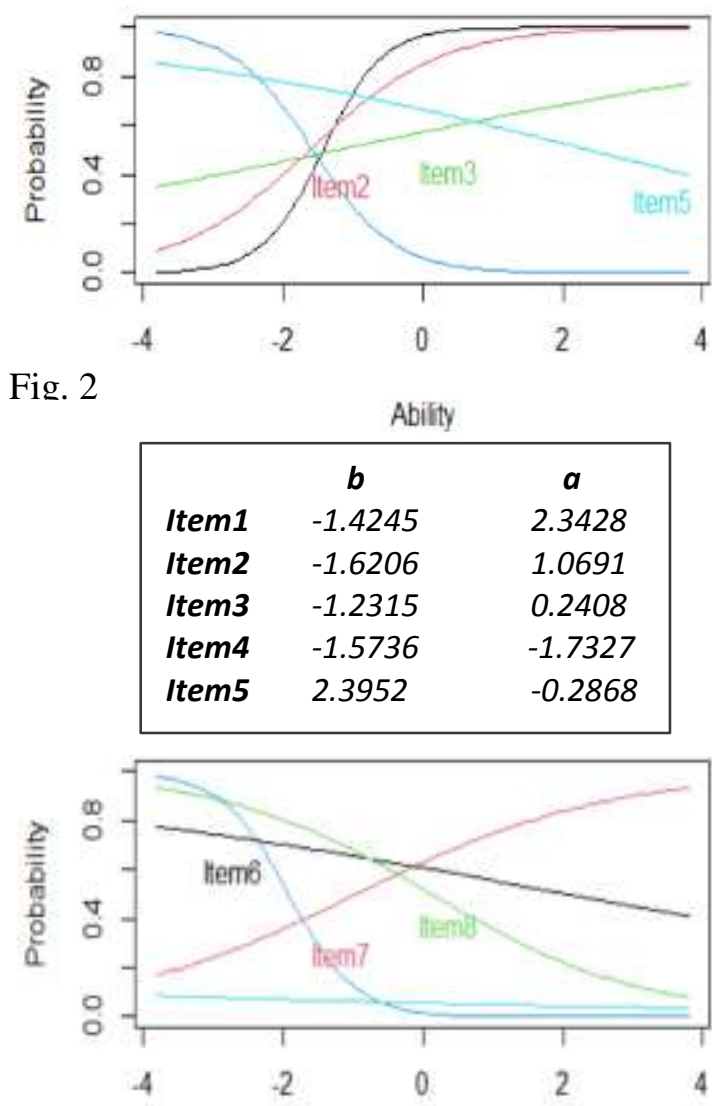

\begin{tabular}{|lcc|}
\multicolumn{3}{c}{ Ability } \\
\hline & $\boldsymbol{b}$ & $\boldsymbol{a}$ \\
Item6 & 2.0669 & -0.2112 \\
Item7 & -0.9459 & 0.5549 \\
Item8 & 0.1339 & -0.6674 \\
Item9 & -1.9204 & -2.0946 \\
Item10 & -22.8480 & -0.1229 \\
\hline
\end{tabular}

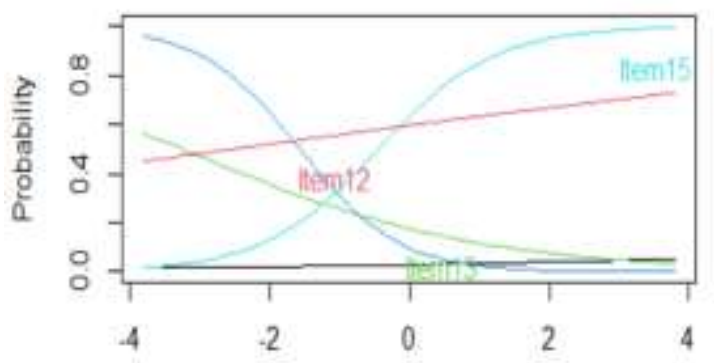

Ability

\begin{tabular}{|ccc|}
\hline & $\boldsymbol{b}$ & $\boldsymbol{a}$ \\
Item11 & 21.6440 & 0.1605 \\
Item12 & -2.5372 & 0.1557 \\
Item13 & -3.2333 & -0.4735 \\
Item14 & -1.5625 & -1.4140 \\
Item15 & -0.4408 & 1.2085 \\
\hline
\end{tabular}


$\boldsymbol{b}$ is Difficulty parameter, $\boldsymbol{a}$ is Discrimination parameter

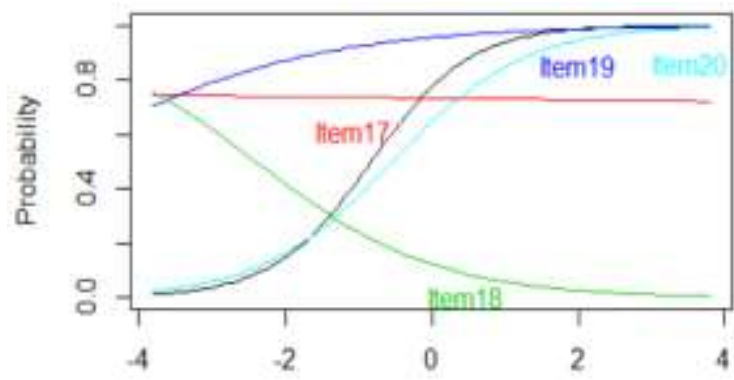

Fig. 7

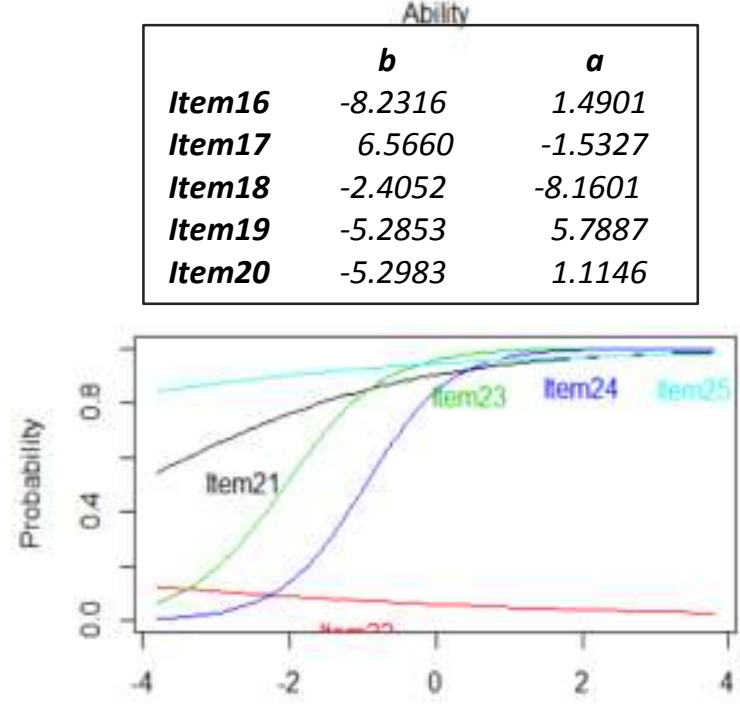

Fig. 9

\begin{tabular}{|ccc|}
\multicolumn{3}{c}{ Ability } \\
\hline & $\boldsymbol{b}$ & $\boldsymbol{a}$ \\
Item21 & -4.1145 & 5.4023 \\
Item22 & -1.3041 & -2.1029 \\
Item23 & -2.0468 & 1.5121 \\
Item24 & -9.5741 & 1.7398 \\
Item25 & -9.2620 & 3.0303 \\
\hline
\end{tabular}

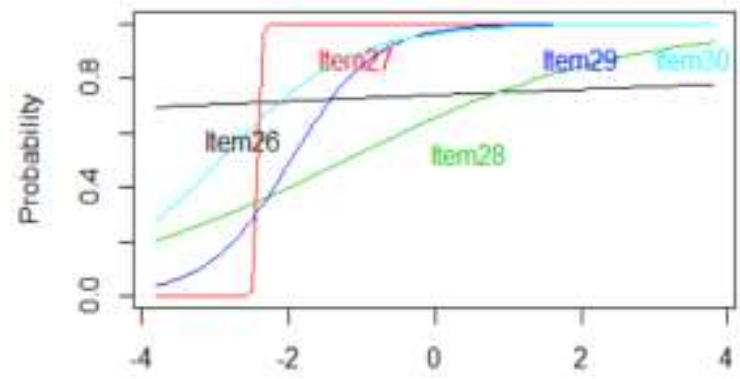

Fig. 11

\begin{tabular}{|ccc|}
\multicolumn{3}{c}{ Ability } \\
\hline & $\boldsymbol{b}$ & $\boldsymbol{a}$ \\
Item26 & -1.8266 & 5.6520 \\
Item27 & -2.4127 & 4.6570 \\
Item28 & -1.2077 & 5.2233 \\
Item29 & -1.9610 & 1.7578 \\
Item30 & -2.9305 & 1.1127 \\
\hline
\end{tabular}

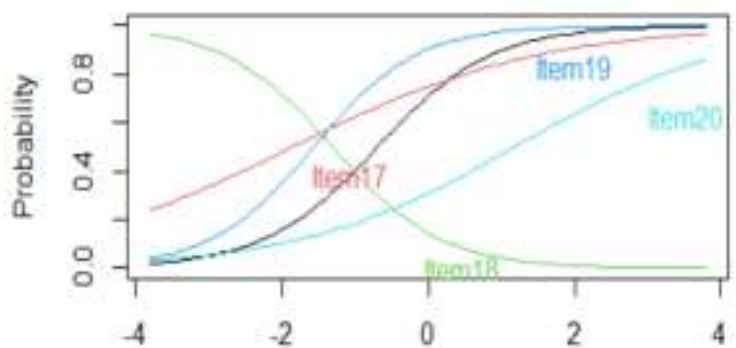

Fig. 8

\begin{tabular}{|ccc|}
\multicolumn{3}{c}{ Ability } \\
\hline & $\boldsymbol{b}$ & $\boldsymbol{a}$ \\
Item16 & -0.6899 & 1.2747 \\
Item17 & -1.8500 & 0.5928 \\
Item18 & -1.3081 & -1.3487 \\
Item19 & -1.5617 & 1.4157 \\
Item20 & 1.1857 & 0.6810 \\
\hline
\end{tabular}

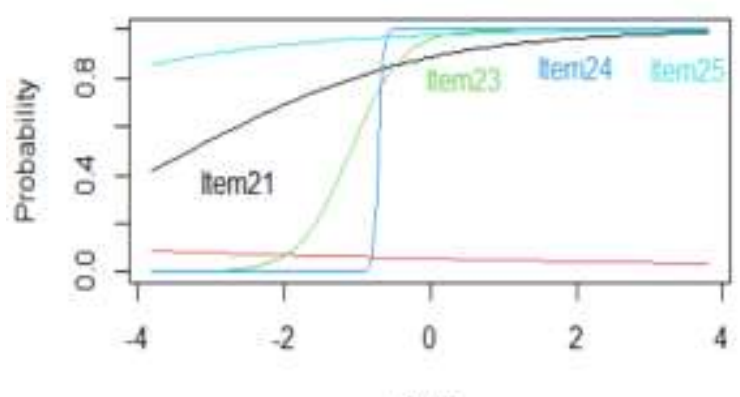

Fig. 10

Ability

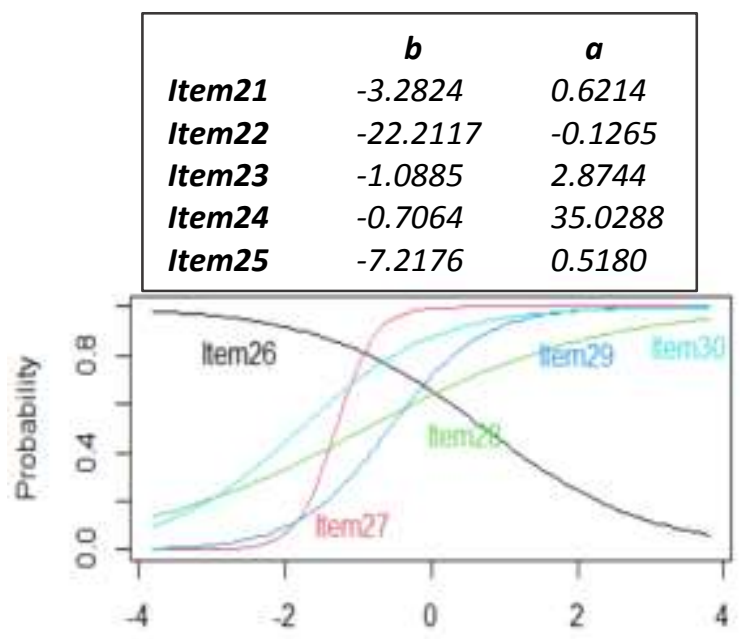

Fig. 12

\begin{tabular}{|ccc|}
\multicolumn{3}{c}{ Ability } \\
\hline & $\boldsymbol{b}$ & $\boldsymbol{a}$ \\
Item26 & 0.7290 & -0.8807 \\
Item27 & -1.3012 & 3.7751 \\
Item28 & -0.8828 & 0.6274 \\
Item29 & -0.5663 & 1.5934 \\
Item30 & -1.7817 & 1.0895 \\
\hline
\end{tabular}


$\boldsymbol{b}$ is Difficulty parameter, $\boldsymbol{a}$ is Discrimination parameter

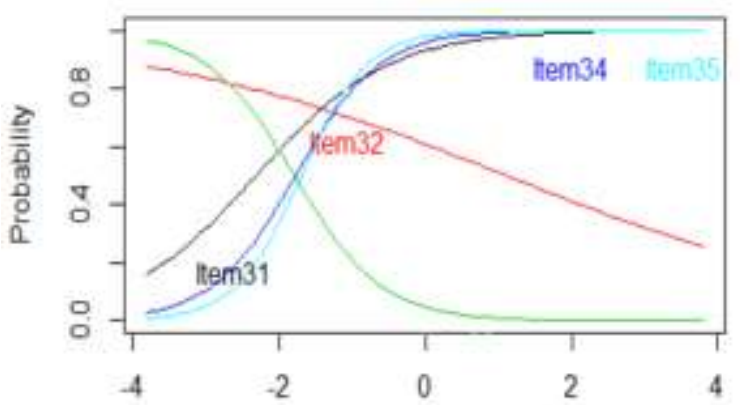

Fig. 13

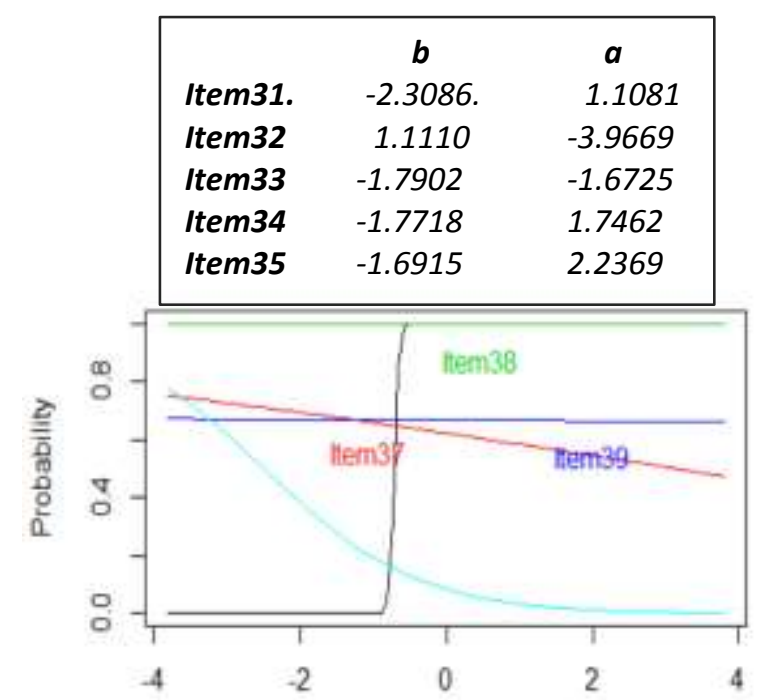

Fig. 15
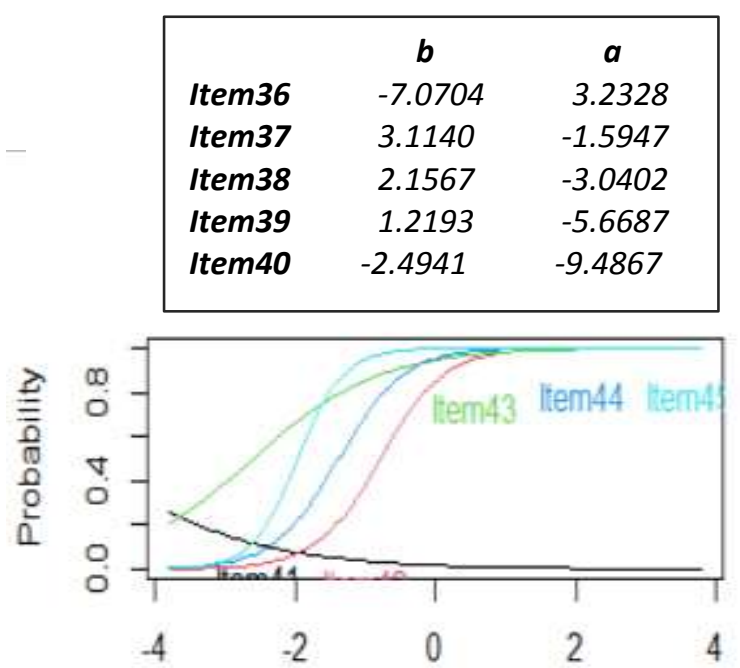

Fig. 17

\begin{tabular}{|ccc|}
\multicolumn{3}{c}{ Ability } \\
\hline & $\boldsymbol{b}$ & $\boldsymbol{a}$ \\
Item41 & -5.1644 & -7.8620 \\
Item42 & -7.9233 & 2.2169 \\
Item43 & -2.5939 & 1.1083 \\
Item44 & -1.3803 & 2.2009 \\
Item45 & -1.9543 & 3.0956 \\
\hline
\end{tabular}

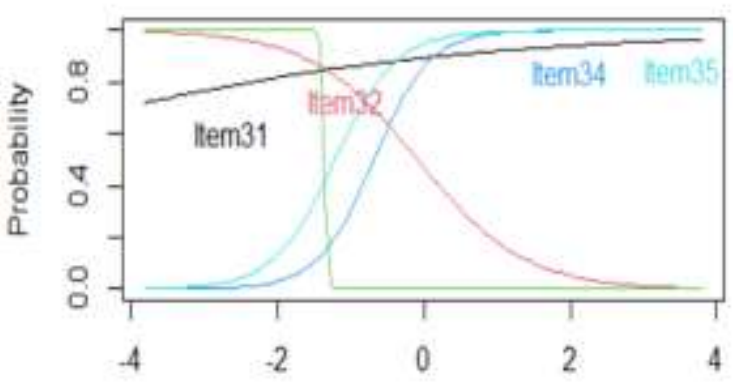

Fig. 14

Ability

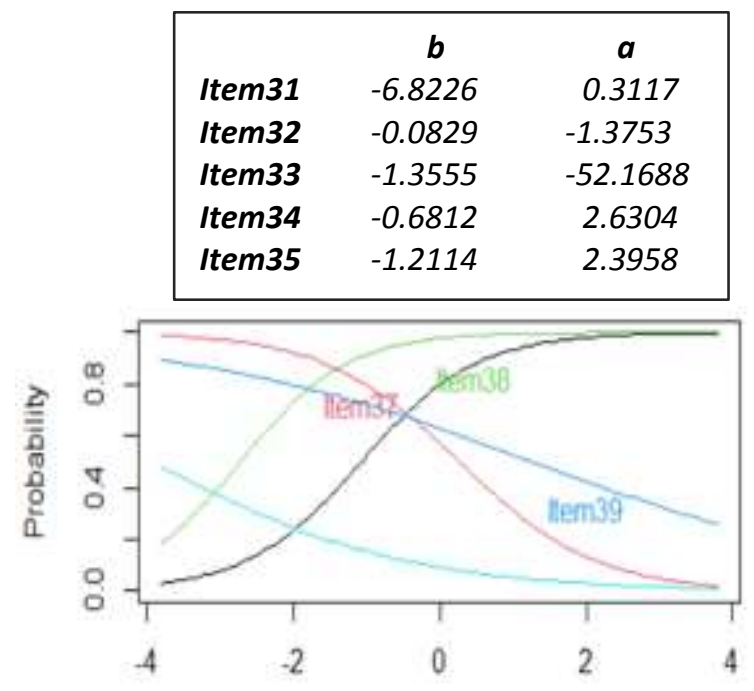

Fig. 16

Ability

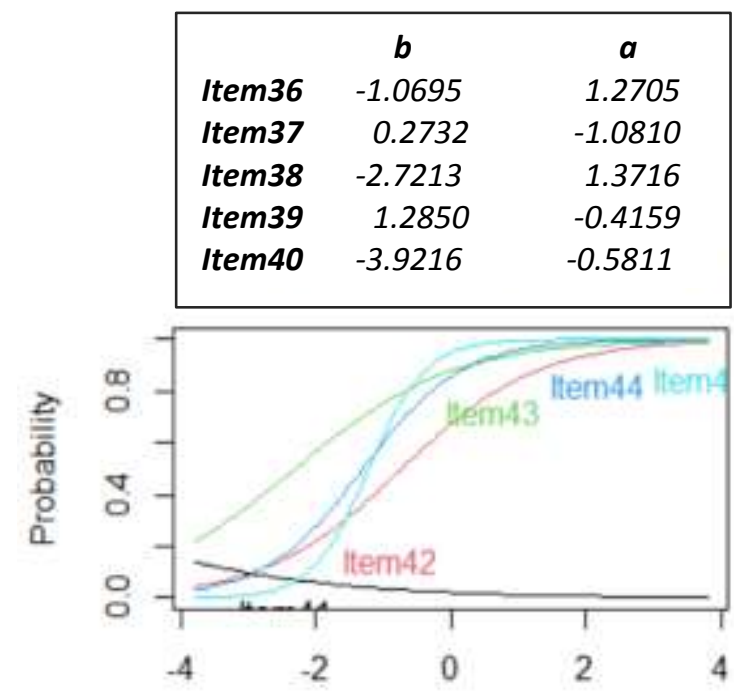

Fig. 18

\begin{tabular}{|ccc|}
\multicolumn{3}{c}{ Ability } \\
& $\boldsymbol{b}$ & $\boldsymbol{a}$ \\
Item41 & -7.3555 & -0.5074 \\
Item42 & -0.7301 & 0.9893 \\
Item43 & -2.3104 & 0.8529 \\
Item44 & -1.3009 & 1.3677 \\
Item45 & -1.2114 & 2.3950 \\
\hline
\end{tabular}

Journal DOI URL: https://doi.org/10.36713/epra2013 
$\boldsymbol{b}$ is Difficulty parameter, $\boldsymbol{a}$ is Discrimination parameter

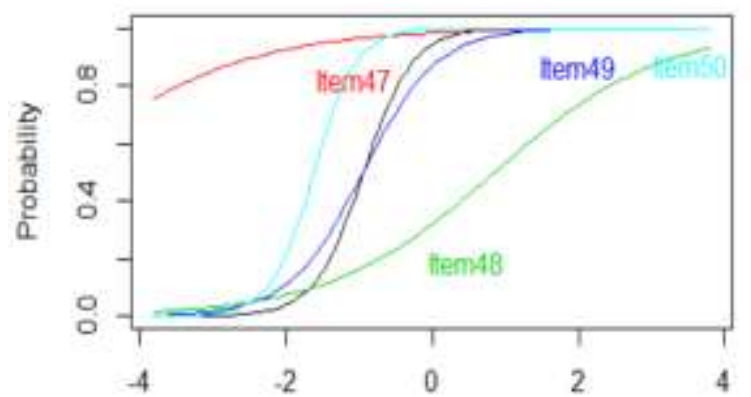

Fig. 19

Ability

\begin{tabular}{|ccc|}
\hline & $\boldsymbol{b}$. &. $\boldsymbol{a}$ \\
Item46 & -9.3421 & 3.0031 \\
Item47 & -5.2662 & 7.6587 \\
Item48 & 8.6065 & 8.8221 \\
Item49 & -9.4457 & 1.9828 \\
Item50 & -1.6190 & 3.4285 \\
\hline
\end{tabular}

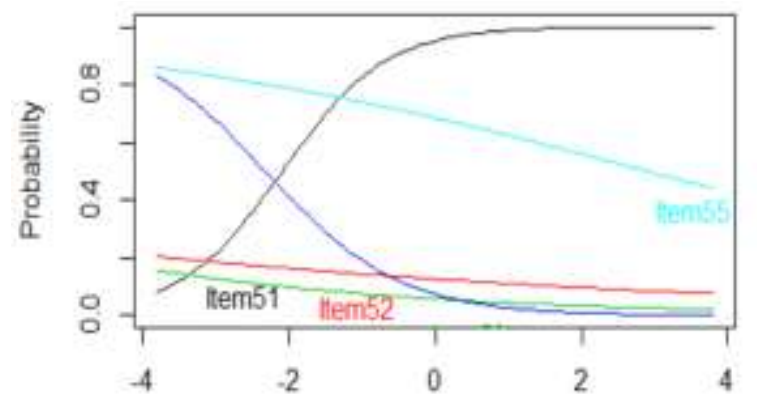

Fig 21

\begin{tabular}{|ccc|}
\multicolumn{3}{c}{ Ability } \\
\hline & $\boldsymbol{b}$ & $\boldsymbol{a}$ \\
Item51 & -2.0889 & 1.4216 \\
Item52 & -1.2856 & -1.5070 \\
Item53 & -9.5780 & -2.9219 \\
Item54 & -2.3285 & -1.0878 \\
Item55 & 2.8992 & -2.6797 \\
\hline
\end{tabular}

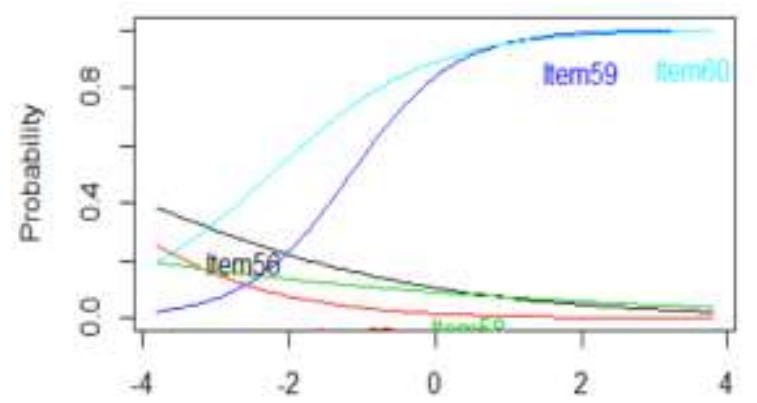

Fig. 23

\begin{tabular}{|ccc|}
\multicolumn{3}{c}{ Ability } \\
\hline Item56 & $\boldsymbol{b}$ & $\boldsymbol{a}$ \\
Item57 & -4.8829 & -4.3656 \\
Item58 & -9.1643 & -7.8620 \\
Item59 & -1.1542 & -2.3287 \\
Item60 & -2.2465 & 1.4130 \\
& & 9.2354 \\
\hline
\end{tabular}

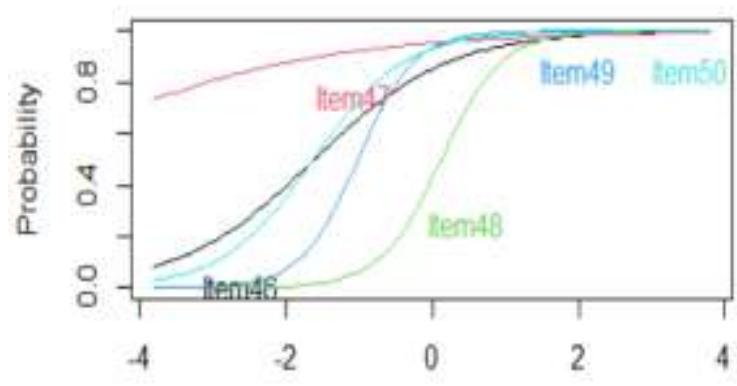

Fig. 20

Ability

\begin{tabular}{|ccc|}
\hline & $\boldsymbol{b}$ & $\boldsymbol{a}$ \\
Item46 & -1.6045 & 1.0893 \\
Item47 & -5.6947 & 0.5297 \\
Item48 & 0.1242 & 2.4240 \\
Item49 & -1.0162 & 2.6003 \\
Item50 & -1.6232 & 1.6056 \\
\hline
\end{tabular}

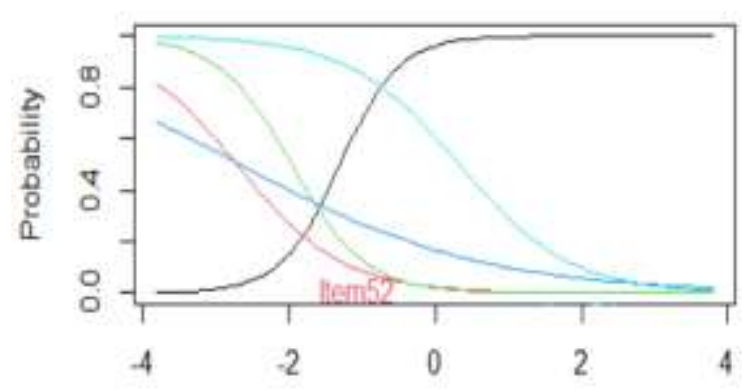

Fig. 22

Ability

\begin{tabular}{|ccc|}
\hline & $\boldsymbol{b}$ & $\boldsymbol{a}$ \\
Item51 & -1.3007 & 2.4752 \\
Item52 & -2.7127 & -1.3785 \\
Item53 & -1.9646 & -1.9884 \\
Item54 & -2.6665 & -0.6007 \\
Item55 & 0.3275 & -1.3277 \\
\hline
\end{tabular}

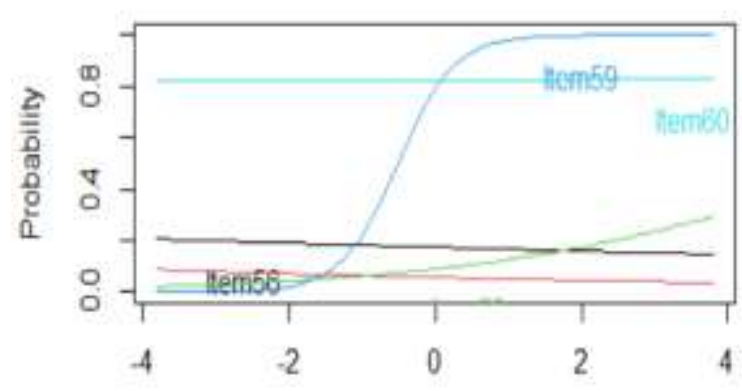

Fig. 24

\begin{tabular}{|ccc|}
\multicolumn{3}{c}{ Ability } \\
\hline & $\boldsymbol{b}$ & $\boldsymbol{a}$ \\
Item56 & -28.6012 & -0.0543 \\
Item57 & -22.8480 & -0.1229 \\
Item58 & 6.0938 & 0.3808 \\
Item59 & -0.5085 & 2.5870 \\
Item60 & -248.9673 & 0.0062 \\
\hline
\end{tabular}


Mantel-Haenszel Chi-square statistic:

\begin{tabular}{|c|c|c|}
\hline & Stat. & P-value \\
\hline Item1. & 0.2707 & 0.6029 \\
\hline Item2. & 0.0208 & 0.8852 \\
\hline Item3. & 2.9442 & 0.0862 . \\
\hline Item4. & 0.2806 & 0.5963 \\
\hline Item5. & 1.9895 & 0.1584 \\
\hline Item7. & 0.0127 & 0.9101 \\
\hline Item8. & 4.1932 & $0.0406 *$ \\
\hline Item9. & 0.0408 & 0.8399 \\
\hline Item10 & 0.1250 & 0.7237 \\
\hline Item11 & 0.0000 & 1.0000 \\
\hline Item12 & 4.0497 & $0.0442 *$ \\
\hline Item13 & 0.2576 & 0.6118 \\
\hline Item14 & 3.7448 & 0.0530 \\
\hline Item15 & 0.1184 & 0.7308 \\
\hline Item16 & 0.7339 & 0.3916 \\
\hline Item17 & 2.0518 & 0.1520 \\
\hline Item18 & 1.6456 & 0.1996 \\
\hline Item19 & 0.5901 & 0.4424 \\
\hline Item 20 & 0.0667 & 0.7963 \\
\hline Item21 & Inf & $0.0000 * *$ \\
\hline Item 22 & Inf & $0.0000 * * *$ \\
\hline Item 23 & 3.9750 & $0.0462 *$ \\
\hline Item24 & 0.0068 & 0.9340 \\
\hline Item 25 & Inf & $0.0000 * *$ \\
\hline Item26 & 1.7410 & 0.1870 \\
\hline Item 27 & 0.0000 & 1.0000 \\
\hline Item28 & 0.1557 & 0.6931 \\
\hline Item29 & 0.2361 & 0.6271 \\
\hline Item30 & 0.1889 & 0.6638 \\
\hline Item31 & 0.0781 & 0.7799 \\
\hline Item32 & 0.1565 & 0.6924 \\
\hline Item33 & 0.1468 & 0.7016 \\
\hline Item34 & 0.0006 & 0.9813 \\
\hline Item35 & 0.0310 & 0.8602 \\
\hline Item36 & 0.0244 & 0.8759 \\
\hline Item37 & 0.0086 & 0.9261 \\
\hline Item38 & 0.0208 & 0.8852 \\
\hline Item39 & 0.1815 & 0.6701 \\
\hline Item40 & 0.1167 & 0.7326 \\
\hline Item41 & 0.1250 & 0.7237 \\
\hline Item42 & 0.3889 & 0.5329 \\
\hline Item 43 & 0.0009 & 0.9761 \\
\hline Item44 & 0.1142 & 0.7354 \\
\hline Item45 & 0.3125 & 0.5762 \\
\hline Item46 & 3.7902 & 0.0516 \\
\hline Item47 & 0.3452 & 0.5569 \\
\hline Item48 & 0.1565 & 0.6924 \\
\hline Item49 & 1.2380 & 0.2658 \\
\hline Item50 & 0.5901 & 0.4424 \\
\hline Item51 & 0.3333 & 0.5637 \\
\hline Item52 & 0.0408 & 0.8399 \\
\hline Item53 & 1.5610 & 0.2115 \\
\hline Item54 & 0.0669 & 0.7960 \\
\hline Item55 & 0.6403 & 0.4236 \\
\hline Item56 & 0.0669 & 0.7960 \\
\hline
\end{tabular}




$\begin{array}{lll}\text { Item57 } & 0.1250 & 0.7237 \\ \text { Item58 } & 0.1250 & 0.7237 \\ \text { Item59 } & 0.1789 & 0.6723 \\ \text { Item60 } & 0.0984 & 0.7537\end{array}$

Significant. codes: $0{ }^{\prime * * * '} 0.001^{\prime} * *$ ' $0.01^{\prime} *{ }^{\prime} 0.05$ '.' $0.1^{\prime}$ ' 1

Detection threshold: 3.8415 (significance level: 0.05)

Items detected as DIF items:

Item8

Item 12

Item 21

Item22

Item 23

Item 25

Looking at the pattern of the result, most of the items are very easy because their standard deviation fell below zero. Out of the 60 items only items 17, 32, 37, 38, 39, 48 and 55 (just about $11.67 \%$ of the total items) showed standard deviation of more than zero when administered on urban JSS 3 students. The pattern of result from the rural students examined also showed that 11 items (items 5, 6, 8, 11, 20, 26, 37, 39, 48, 55 and 58) have difficulty indices above zero out of the 60 item, representing about $18.33 \%$. From this result the urban JSS3 students has better chance of passing when compared to their counterparts in the rural areas.

In comparison, 39 items $(1,2,3,4,5,6,7,8,9,11,14,15,16,18,19,20,21,23,24,25,26,27,28,29$, $30,33,34,35,36,39,42,43,44,45,46,49,53,58$ and 59) were found to be easier for the urban JSS3 students while 21 items $(10,12,13,17,22,31,32,37,38,40,44,47,48,50,51,52,54,55,56$, 57, and 60) were also found to be easier for the rural subgroup.

Discrimination parameter is an index that shows how good an item is in classifying examinees either below or above the difficulty parameter of an item. Normally an index of 1.00 is ideal. Items having indices greater than 1.00 are better but less than 1.00 are not good discriminators. On separate administration of the instrument to both urban and rural JSS3 students and after analysis, varying discrimination indices were obtained ranging from negative to positive values. Out of the 60 items administered the urban students 28 items $(4,8,9,10,11,13,14,17,22,32,33,37,38,39,40,41,52,53,54,55,56,57$ and 58) had negative discrimination indices while the rest had positive indices. After administering to the rural student it was also found that 23 items $(4,5,6,8,9,10,13,14,18,22,26,32,33,37,39,40,41,52,53,54,55,56$ and 57) had negative discrimination indices.

\section{DISCUSSION}

From the results of the analyses, both groups of students responded to the 2019 BECE basic science items. It was found that each of the items had differing difficulty indices as the two subgroup of students were measured. The results showed that rural students encountered more difficult items (11) than their urban counterparts who had only seven (7) items out of 60 . The remaining items with standard deviation less than zero also showed differential difficulty indices between the two groups examined.

It was also discovered that all the items varied in discrimination indices between the two groups examined. Some values were positive while others were negative. In the urban students' assessment, 28 items had negative value while in the rural students', 23 items were found to have negative value out of 60 items. Items with negative discrimination indices are not good discriminations.

The sensitivity of DIF detection method varies among the multitude available. In this study, the Mantel-Haenszel (M-H) method was used. The M-H method has the ability to detect uniform DIF without using item response approach (Holland \& Thayer, 1988). The M-H DIF analysis result showed each item's value (chi-square statistic and corresponding P-value). A total of six items (items 5, 12, 21, 22, 23, and 25) were flagged as DIF items. Based on the presence of the six DIF items, the null hypothesis was rejected.

\section{CONCLUSION AND RECOMMENDATION}

From the findings of the study, items of the 2019 basic science BECE exhibited DIF when used during examination. This test was slightly easier for urban students and more difficult for rural students. In the light of this finding, it is recommended that before such and similar test items are used to assessment, thorough 
investigation of items be conducted for possible DIF. If any item is flagged as DIF, it should be edited or eliminated to ensure the right quality instrument is designed and used. The same learning experiences should be provided for all JSS3 students across the state, as against the preferences enjoyed by the urban students.

\section{REFERENCES}

1. Babcock, B., \& Albano, A. D. (2011), Rasch scale drift over time. Examining when to reset the sacle. Paper presented at National Council on Measurement in Education, New Orleans L. A.

2. Bock, Muraki E., \& Pfeiffenberger W. (1988). Ham, pool maintenance in the presence of item parameter drift. Journal of Educational measurement, 25(24), 275-285.

3. Bulut, O., Stanke, L., Rodrignez, M.C, Palma, J. R., Vue, K., \& Cabrena, J.C. (2013). Examining Item paramater Drift as a source of construct shift.

4. Goldstein, H. (1983). Measuring changes in educational attainment over time: Problems and possibilities. Journal of Educational Measurement, 20, 369 -377.

5. Holland, P. W \& Wainer H., (1993). Differential Item Functioning. Rontledge, London UK.

6. Holland, P. W., and Thayer, D. T. (1988). Differential item performance and the Mantel-Haenszel procedure. In H. Wainer and H. I. Braun (ed.), Text validity. Hill sidale, NJ: Lawrence Erlbaum Associates.

7. Li, X. (2008). An investigation of the item parameter drift in the examination for the certificate of proficiency in English (ECPE). SPAAN FELLOW, 1001, 1

8. Pine S. N., (1977). Application of item chracteristic curve theory to the problem of test bias. In Wollack, J. A., Sung, H. J., \& Kang, T., (2005) Longitudinal effect of item parameter drift. Paper presented at the annual meeting of the National council; on Measurement in education. Montreal, Canada.

9. Rizopoulos, D. (2006) Itm: An R package for latent variable modelling and item response theory analyses. Journal of Statistical Software, 17(5), 1-25. URL http://www.jstatoft.org/v17/i05/.

10. Wollack sung, H.J \& kang, T, (2006). The impact of compounding item parameter drift on ability estimation. Paper presented at annual meeting of the National Council on Measurement in Education, san francisco 